\title{
Model-based analysis of spatio-temporal changes in land use in Northeast China
}

\author{
XIA Tian ${ }^{1,2},{ }^{*}$ WU Wenbin ${ }^{1,2}$, ZHOU Qingbo², Peter H. VERBURG ${ }^{3}$, YU Qiangyi², \\ YANG Peng ${ }^{2}$, YE Liming ${ }^{4,5}$
}

1. Key Laboratory for Geographical Process Analysis \& Simulation, Hubei Province / College of Urban \& Environmental Sciences, Central China Normal University, Wuhan 430079, China;

2. Key Laboratory of Agri-Informatics, Ministry of Agriculture / Institute of Agricultural Resources and Regional Planning, Chinese Academy of Agricultural Sciences, Beijing 100081, China;

3. Institute for Environmental Studies, VU University Amsterdam, de Boelelaan 1085, 1081 HV Amsterdam, The Netherlands;

4. CAAS-UGent Joint Laboratory of Global Change and Food Security / Institute of Agricultural Resources and Regional Planning, Chinese Academy of Agricultural Sciences, Beijing 100081, China;

5. Department of Geology and Soil Sciences (WE13), Ghent University, 9000 Gent, Belgium

\begin{abstract}
Spatially explicit modeling techniques recently emerged as an alternative to monitor land use changes. This study adopted the well-known CLUE-S (Conversion of Land Use and its Effects at Small regional extent) model to analyze the spatio-temporal land use changes in a hot-spot in Northeast China (NEC). In total, 13 driving factors were selected to statistically analyze the spatial relationships between biophysical and socioeconomic factors and individual land use types. These relationships were then used to simulate land use dynamic changes during 1980-2010 at a $1 \mathrm{~km}$ spatial resolution, and to capture the overall land use change patterns. The obtained results indicate that increases in cropland area in NEC were mainly distributed in the Sanjiang Plain and the Songnen Plain during 1980-2000, with a small reduction between 2000 and 2010. An opposite pattern was identified for changes in forest areas. Forest decreases were mainly distributed in the Khingan Mountains and the Changbai Mountains between 1980 and 2000, with a slight increase during 2000-2010. The urban areas have expanded to occupy surrounding croplands and grasslands, particularly after the year 2000. More attention is needed on the newly gained croplands, which have largely replaced wetlands in the Sanjiang Plain over the last decade. Land use change patterns identified here should be considered in future policy making so as to strengthen local eco-environmental security.
\end{abstract}

Keywords: land use change; CLUE-S; Northeast China; two-way simulation

Received: 2015-05-25 Accepted: 2015-09-16

Foundation: National Natural Science Foundation of China No.41201089; No.41271112; The Fundamental Research Funds for the Central Universities, No.CCNU15A05058; National Nonprofit Institute Research Grant of CAAS, No.IARRP-2015-28

Author: Xia Tian (1981-), Associate Professor, specialized in remote sensing monitoring and simulation of the influence of the global changes in agriculture. E-mail: xiatian@mail.ccnu.edu.cn

"Corresponding author: Wu Wenbin, Professor, E-mail: wuwenbin@caas.cn 


\section{Introduction}

Human land use practices have transformed a large proportion of the planet's land surface (Wu et al., 2007), and have major consequences for the environment through the alteration of the structure and functioning of ecosystems, and influences how ecosystems interact with the atmosphere, aquatic systems and surrounding land (Foley, 2005). Thus, the land system science community has sought to understand land use dynamics over time, space and scale (Turner II et al., 2013; Verburg et al., 2013). Considerable researches have investigated and analyzed past and present geographic distributions of land use and its dynamics with the aid of remote sensing, statistical methods and a combination of these (Gong et al., 2013; Gutman et al., 2013; Sleeter et al., 2013; Verburg et al., 2011; Wu et al., 2008). However, these studies are often labor intensive and time consuming, especially when applied to large areas. Land use changes are driven by a number of biophysical and socioeconomic factors (Lambin et al., 2001). When these factors are properly identified from past and present observations, and the causal relationships between these factors and land use changes are well constructed, changes in land use can be modeled using these derived relationships (Rounsevell M D A et $a l ., 2006)$. Spatially explicit modeling techniques thus recently emerge as an alternative to monitoring and mapping approaches, as they are capable of representing land use change and its possible directions (Yu et al., 2012).

Many studies have used a modeling approach to evaluate land use changes and their effects over multiple scales (Letourneau et al., 2012; Rounsevell et al., 2003; Schaldach et al., 2011; Veldkamp et al., 1996; Verburg et al., 2002; Verburg et al., 2006). The methods used, which often require modification for local conditions, are normally either process-based (e.g., an economic or agent-based model) or pattern-based (e.g., a machine learning model) (Brown et al., 2013). Process-based models are often derived from micro- or macroeconomic theory, or use a multi-agent simulation approach (Verburg et al., 2004). They normally start from the viewpoint of individual landowners who make land use decisions with the objective of maximizing expected returns or utility derived from the land (Lambin et al., 2006). The challenge is to obtain sufficient data at the individual/household level to develop a well-parameterized and validated model of decision making. The behavioral assumptions are then valid for micro-level analysis, which restricts these models only be used in a small area. Conversely, pattern-based models, such as the CLUE-S model (Verburg, 2002), GEOMOD2 (Pontius Jr et al., 2001) and LOV (White et al., 2000), usually rely on empirical-statistical approaches to analyze the spatial structure of land use change. The underlying assumption is that the observed spatial relations between land use types and their driving forces represent currently active processes, and will remain valid in the future. This flexible approach is helpful in identifying key processes, and thus facilitates an understanding of the dynamic behavior of land use patterns on a large scale, or for some "hot-spot" areas (Bakker et al., 2012; Li et al., 2012).

Northeast China (NEC), located at relatively high latitudes $\left(38^{\circ} 40^{\prime} \mathrm{N}-53^{\circ} 34^{\prime} \mathrm{N}\right)$ (Figure 1), is such a "hot-spot" area with vast importance for Chinese food and ecological security. It covers a total territory of $791,800 \mathrm{~km}^{2}$ and comprises Heilongjiang, Jilin, and Liaoning provinces. Most areas in NEC have a humid or semi-humid monsoon climate with annual temperatures ranging from -6 to $11^{\circ} \mathrm{C}$. The average annual rainfall in this region ranges from 400 to $1,000 \mathrm{~mm}$ and the spatial pattern of rainfall decreases from the southeast to the 
northwest, with most rain falling in July and August (Li Z. et al., 2012). Among the major grain production regions in China, NEC is considered as the region most susceptible to global environmental change. Continuous measurements from meteorological stations indicate that NEC has experienced a warming trend, with an average surface temperature increase of $0.38^{\circ} \mathrm{C}$ per decade over the past five decades (Gao et al., 2011; Wu et al., 2014). Previous studies in NEC also show that a large proportion of the land surface has been converted from one land use type to another. For instance, conversions from grassland and wetland to cropland (Liu et al., 2005), together with modifications within cropland, have resulted in a high growth in rice production, particularly over the past 30 years, during which period it has increased from $3 \%$ to $13 \%$ of China's total rice production (Xia et

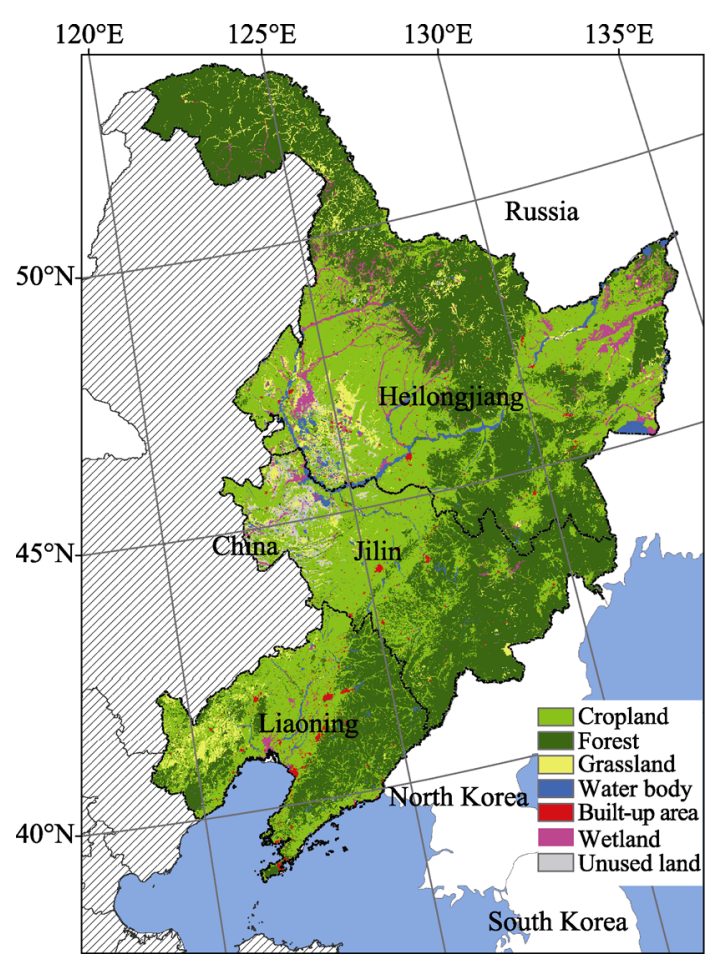

Figure 1 Land use in Northeast China in 2000. al., 2014). Furthermore, NEC has also experienced great socioeconomic changes, e.g., land tenure reforms and widespread adoption of agricultural mechanization and intensification (Yu et al., 2013).

Some studies have analyzed past land use changes in NEC mainly by using remotely sensed images (Liu et al., 2005; Liu et al., 2003). Unfortunately, detailed analyses of the patterns of land use changes in NEC are scarce. Understanding and modeling these land use changes is critical, as this can provide important information about the scope and impact of land use changes, and can support the analysis of the vulnerability of ecosystems and provide insight into how land use might respond to a range of environmental changes. The objective of this study is thus to analyze the spatio-temporal changes in land use in NEC over the period of 1980-2010. To do so, a classic pattern-based modeling approach was used to identify the possible determinants of land use distribution in NEC, and to simulate the dynamic changes in land use over the period of 1980-2010 at a resolution of $1 \mathrm{~km}$, and further to capture the overall patterns of land use changes.

\section{Data and methods}

\subsection{Data}

A considerable amount of input data, including both spatial and nonspatial data, were used in this study (Table 1). Spatial datasets included satellite-based land use, a digital elevation model (DEM), temperature, precipitation, soil, roads (levels 1 to 3, China highway classification), rivers, residential areas, population and GDP. Most of these data were collected 
around the baseline year of 2000. Satellite-derived land use data in 2000 were used as a baseline map to analyze the spatial relationships between land use types and 13 selected biophysical and socioeconomic factors. Two additional land use maps in 1990 and 2005 were used for model validation. Nonspatial data mainly comprise the yearly land requirement for individual land use types. This was compiled from China Statistical Yearbooks and aggregated at the regional level, and then used as the land use demands in a spatial allocation model. All spatial data were converted into GIS grid data with a cell size of $1 \mathrm{~km}$ by 1 $\mathrm{km}$ in a standard GIS software environment (ESRI ArcGIS 9.3). DEM data were processed to generate aspect and slope. FAO soil data were further divided into 20 soil types according to the soil classification, and each soil type was used as a driving factor in spatial analysis (The names of soil classes are shown in Table 3, designated as Soil_1 to Soil_20) (Ye et al., 2008).

Table 1 List of input data used in this study

\begin{tabular}{|c|c|c|c|}
\hline Variable & Description & Resolution & Source \\
\hline Land use data & $\begin{array}{l}\text { Remote sensing of land use patterns in 1990, } 2000 \\
\text { and } 2005 \text { (including cropland, forest, grassland, } \\
\text { water body, built-up area, wetland and unused land) }\end{array}$ & $1 \mathrm{~km}$ & $\begin{array}{l}\text { Institute of Geographic } \\
\text { Sciences and Natural } \\
\text { Resources Research } \\
\text { (IGSNRR), CAS }\end{array}$ \\
\hline DEM & Spatial data, used to generate the aspect and slope & $1 \mathrm{~km}$ & IGSNRR, CAS \\
\hline Temperature & $\begin{array}{l}\text { Years average temperature; annual accumulated } \\
\text { temperature } \geqslant 0{ }^{\circ} \mathrm{C} \text {; annual accumulated tempera- } \\
\text { ture } \geqslant 10^{\circ} \mathrm{C}\end{array}$ & $500 \mathrm{~m}$ & $\begin{array}{l}\text { China Meteorological } \\
\text { Administration }\end{array}$ \\
\hline Rainfall & Years average rainfall & $1 \mathrm{~km}$ & $\begin{array}{l}\text { China Meteorological } \\
\text { Administration }\end{array}$ \\
\hline Soil & Map; soil type (subclass) distribution & & FAO soil classification \\
\hline Road & Level $1 \sim 3$ traffic network distribution & & National Fundamental GIS \\
\hline River & River water distribution & & National Fundamental GIS \\
\hline Residential area & Residential distribution & & National Fundamental GIS \\
\hline Population & $\begin{array}{l}\text { Demographic data distribution map, } 1 \mathrm{~km} \text { grid, } \\
\text { population: people } / \mathrm{km}^{2}\end{array}$ & $1 \mathrm{~km}$ & IGSNRR, CAS \\
\hline GDP & $\begin{array}{l}\text { Data distribution diagram, } 1 \mathrm{~km} \text { grid, GDP unit: } \\
\text { million yuan } / \mathrm{km}^{2}\end{array}$ & $1 \mathrm{~km}$ & IGSNRR, CAS \\
\hline $\begin{array}{l}\text { Land use } \\
\text { requirements }\end{array}$ & 7 land use types, provincial level, 1980-2010 & l & $\begin{array}{l}\text { China Statistical } \\
\text { Yearbooks }\end{array}$ \\
\hline
\end{tabular}

\subsection{Model-based analysis}

\subsubsection{CLUE-S model}

The well-known CLUE-S (Conversion of Land Use and its Effects at Small regional extent) model was adopted for this study. CLUE-S is a spatially explicit land use model that simulates the dynamic competition between different land use types. The model functions through the spatial allocation of aggregated demands for different land use types to individual grid cells across multiple time and space scales. The computational core of CLUE-S is a top-down allocation module, which allocates the aggregated land claim to the cells year by year in an iterative way. These land use demands impose the quantity of land use change for each land use type. The allocation module incorporates various mechanisms that determine the distribution of land use types appropriate for any given landscape. These mechanisms are 
parameterized as three categories of model settings and inputs, i.e., location suitability, spatial policies and restrictions, and conversion settings. These three categories together define the preferences and constraints from which the allocation routine determines an optimal solution and assigns a land use type to each grid cell. Detailed descriptions of CLUE-S can be found in (Verburg, 2002; Verburg et al., 2006).

\section{Model simulation}

In this study, CLUE-S was run over a period of 30 years (1980-2010), taking the year 2000 as the baseline due to reliable data sources. To ensure realistic and consistent simulated results for land use change analysis, a forward simulation was run for the period of 2000-2010 and a backward simulation was run for the period of 1980-2000. The forward simulation was a simple application of CLUE-S, while the backward simulation was different from the normal application, with some settings and adjustments modified as described below.

\section{Land use requirements (demand)}

Land use requirements define the aggregated demands for different land use types, which were input into CLUE-S for spatial allocation. Generally, aggregated land use demands can be either extrapolated from historical data or projected for complex economic models. In this study, seven land use types, i.e., cropland, forest, grassland, water body, built-up area, wetland and unused land, were included in the analysis, and their yearly land demands at the regional level were obtained from China Statistical Yearbooks.

\section{Spatial policies and restrictions}

Spatial policies and restrictions indicate the specific areas where land use changes are restricted. For instance, in the cropland protection zone in NEC, croplands are firmly protected, and it is prohibited to convert them into other land use types. Moreover, the primary forests in the Great Khingan and Lesser Khingan Mountains remain as permanent nature reserves following the regulations of the Khingan Mountains ecological nature reserve. All these areas were restricted to their current land uses in the simulation process.

\section{Land use conversion settings}

Conversion elasticity and transition sequences are set for individual land use types. Conversion elasticity defines the reversibility of land use changes, while transition sequences control the various types of land use conversions by a transition matrix. In this study, since the CLUE-S model was run both forward and backward, these two parameters were set independently for forward and backward simulation. Table 2 shows the elasticity coefficients used in this study. It can be seen that built-up areas can rarely be converted into other land use types in the forward simulation, but they are easily converted from others in the backward simulation. To reflect this, the elasticity coefficients were set as 0.9 for forward and 0.5 for backward, respectively.

Table 2 Settings of conversion elasticity

\begin{tabular}{cccccccc}
\hline Simulation & Cropland & Forest & Grassland & Water body & Built-up area & Wetland & Unused land \\
\hline Backward & 0.6 & 0.8 & 0.7 & 0.8 & 0.5 & 0.7 & 0.8 \\
Forward & 0.6 & 0.8 & 0.5 & 0.9 & 0.9 & 0.7 & 0.4 \\
\hline
\end{tabular}




\section{Location characteristics}

Location characteristics describe the local suitability for individual land uses under a given selection of location factors. In this study, a binary logistic regression model was used to determine the driving factors for each land use type in 2000. Binary logistic regression is very often used to explore the casual relationship between predetermined variables and changes in land use (Geoghegan et al., 2001; Serneels et al., 2001) using the following formula.

$$
\operatorname{Logit}\left(p_{i}\right)=\ln \left(p_{i}\right) /\left(1-p_{i}\right)=\beta_{0}+\beta_{1} X_{1}+\beta_{2} X_{2}+\ldots+\beta_{n} X_{n},
$$

where $p_{i}$ is the probability of a grid cell being land use type $i$ and $X i$ are $n$ variables selected as the driving factors, which could be either physical or socioeconomic. Coefficients $(\beta)$ are estimated through binary logistic regression using the grid-based land use data as the dependent variable and the selected driving factors as independent variables.

In this study, a total of 13 driving factors (including 11 biophysical factors and two socioeconomic factors) were included to statistically analyze the driving factors of land use changes in NEC (a detailed explanation of driving factors is presented in the Results section). The goodness of fit of the logistic regression models was evaluated using the receiver operating characteristic (ROC), which ranges between 0.5 (completely random) and 1.0 (perfect fit) (Pontius Jr et al., 2001). The most important factors influencing the spatial distribution of land use were identified from the logistic regression as those with a confidence level greater than $95 \%(a \leqslant 0.05)$. These significant factors and coefficients from the logistic regression analysis were combined to determine the location suitability of the seven land use types, which were then used in the spatial allocation.

\subsubsection{Model validation}

In this study, model validation was performed in two ways. First, CLUE-S model simulation results were compared with Null model simulation results in 1990 and 2005 (Pontius et al., 2004). When the CLUE-S model has higher simulation accuracy than the Null model, the model simulation of land use changes is judged to have scientific implications (van Vliet et al., 2011). Second, the satellite-derived land use datasets for 1990 and 2005 were employed as reference data for validating backward and forward simulation results, respectively. The degree of similarity between simulated and measured values at a regional level indicates whether the CLUE-S model simulation follows the patterns identified by satellite observation. As there is no generally agreed method for evaluating the goodness of fit of a simulation model, a quantitative method developed by Costanza R (1989) was used here. Since measurement at one resolution is unable to effectively determine the performance of a model in estimating complex land use patterns, this method determines the overall accuracy of a model by looking at its simulation accuracy at multiple resolutions. A multiple resolution method can yield additional information that is not contained in single resolution methods, and is necessary to adequately evaluate the performance of complex ecological models (Costanza, 1989).

\subsubsection{Spatial analysis}

Simulated results for the period of 1980-2010 were overlaid to analyze the general spatio-temporal changes in land use in NEC. The period was divided into three stages: 
1980-1990, 1990-2000 and 2000-2010. The overlaid maps were further used to identify the area and spatial changes in individual land use types in that period. Moreover, some regions with typical land use changes were identified based on a detailed analysis.

\section{Results and analysis}

\subsection{Statistical regression in $\mathbf{2 0 0 0}$}

Table 3 lists the statistically significant driving factors of land use based on logistic regression. In general, the spatial distributions of the seven land use types were statistically well explained by the selected factors, as indicated by high ROC values (ranging from 0.82 to 0.98).

The highest ROC values were for built-up areas (0.98) and unused land (0.97). Not surprisingly, built-up areas are largely influenced by socioeconomic factors, such as higher GDP, more population, rural residential areas and proximity to highways. Rainfall and slope are also important factors in the selection of built-up locations. Unused land is mainly located in areas that have a long distance from cities and in unsuitable environments with higher elevations (DEM). High to moderate ROC values were found for forest (0.95), water body (0.94) and cropland (0.93). It can be seen from Table 3 that forest in NEC is positively correlated with higher elevation, lower GDP, sparsely populated locations and more rainfall. Distribution of water bodies is positively correlated with lower elevation, lower population and annual accumulated temperature $\geqslant 0{ }^{\circ} \mathrm{C}$. The regression results show that southward location, low altitude, low slope, annual accumulated temperature $\geqslant 10^{\circ} \mathrm{C}$ and higher population are the major factors that influence the spatial distribution of cropland. Soil type also has a certain influence on cropland, which agrees with previous studies (Chen et al., 2013; Yao et al., 2015; Zhang et al., 2011). Finally, wetland (0.90) and grassland (0.82) have relatively low ROC values. The factors for wetland are quite similar to those of unused land, as wetland is normally considered to be a specific form of unused land in China. Grassland in NEC is broadly disseminated and highly mixed with other land use types. It is also relatively difficult to describe its spatial characteristics by using location factors.

\subsection{Model validation in 1990 and 2005}

Figure 2 compares analysis between the model simulation and the satellite observation for year 1990 and 2005. It can be seen that although there were some places where the model simulation deviated somewhat from the satellite observation, in general the simulated and observed land use maps were similar to each other. A comparison indicates that the overall accuracy of CLUE-S simulation is 0.92 and 0.89 for 1990 and 2005, respectively. The Null model has an accuracy of 0.90 and 0.81 for 1990 and 2005, respectively, i.e. lower than that of the CLUE-S model. This suggests that the CLUE-S model has the potential to simulate land use changes. The comparison also shows that the backward simulation has a relatively higher accuracy than the forward simulation. This is due primarily to the difference in the spatial resolution of the reference data used for validation. From the evaluation results described above, it can be concluded that the localized CLUE-S model appears to be adequate 
for the purpose for which it was designed, and it appears to be useful for the analysis of long-term land use changes in NEC.

Table $3 \beta$ values of location factors in regression results related to each land use type; significant coefficients $(\mathrm{P}<0.05)$ are listed

\begin{tabular}{|c|c|c|c|c|c|c|c|}
\hline & Cropland & Forest & Grassland & $\begin{array}{l}\text { Water } \\
\text { body }\end{array}$ & $\begin{array}{l}\text { Built-up } \\
\text { area }\end{array}$ & $\begin{array}{c}\text { Unused } \\
\text { land }\end{array}$ & Wetland \\
\hline Constant & 47.08 & 18.38 & 90.53 & -181.19 & -2.55 & -111.15 & -82.06 \\
\hline Aspect & 0.0015 & -0.0045 & 0.0028 & 0.0051 & -0.0020 & 0.0020 & 0.0038 \\
\hline Elevation (DEM) & -0.0029 & 0.0025 & -0.0004 & -0.0076 & n.s. & 0.0040 & -0.0036 \\
\hline GDP & 0.0008 & -0.0033 & 0.0034 & 0.0021 & 0.0126 & -0.0006 & -0.0034 \\
\hline POP & 0.0076 & -0.0044 & -0.0043 & -0.0061 & 0.0023 & -0.0042 & -0.0022 \\
\hline Rainfall & -0.0003 & 0.0006 & -0.0008 & n.s. & -0.0004 & -0.0011 & -0.0004 \\
\hline Distance to residential area & 0.0006 & 0.0007 & 0.0022 & -0.0019 & -0.0030 & -0.0024 & 0.0020 \\
\hline Distance to river & 0.0004 & 0.0007 & 0.0003 & -0.0034 & n.s. & 0.0030 & -0.0016 \\
\hline Distance to road & n.s. & n.s. & n.s. & 0.0004 & 0.0004 & n.s. & n.s. \\
\hline Slope & -0.0295 & 0.0565 & -0.0231 & -0.0310 & -0.0213 & -0.1249 & -0.0724 \\
\hline $\begin{array}{c}\text { Annual accumulated } \\
\text { temperature } \geq 00^{\circ} \mathrm{C}\end{array}$ & -0.0539 & -0.0848 & -0.0772 & 0.3433 & n.s. & 0.3600 & -0.3730 \\
\hline $\begin{array}{l}\text { Annual accumulated } \mathrm{t} \\
\text { emperature } \geq 10^{\circ} \mathrm{C}\end{array}$ & 0.0066 & 0.0627 & -0.0100 & -0.1623 & n.s. & -0.2558 & 0.2983 \\
\hline Annual mean temperature & 0.0271 & n.s. & 0.0301 & -0.0694 & n.s. & n.s. & 0.0218 \\
\hline I-Bb-U-C (Soil_1) & 0.7175 & 0.3696 & -1.0162 & n.s. & n.s. & 3.3157 & 1.2644 \\
\hline AO13-3bc (Soil_2) & -0.1009 & 1.3624 & -0.5527 & 0.3061 & 0.9438 & 4.2715 & n.s. \\
\hline Ge63-2/3a (Soil_3) & 0.1418 & 0.6060 & 2.5921 & n.s. & n.s. & 1.8103 & n.s. \\
\hline A080-2bc (Soil_4) & 1.0788 & n.s. & -0.5358 & 0.6740 & -1.1014 & 2.4519 & 1.0878 \\
\hline I-Lo-2c (Soil_5) & 0.2481 & 0.4874 & 1.1863 & n.s. & n.s. & 2.9629 & n.s. \\
\hline Kh1-2b (Soil_6) & 0.5820 & 0.9661 & n.s. & n.s. & 7.8537 & 6.0074 & n.s. \\
\hline GL (Soil_7) & -0.8421 & 1.6314 & 2.3325 & n.s. & n.s. & n.s. & -5.0107 \\
\hline Be87-2ab (Soil_8) & -0.3598 & 0.8706 & 2.8974 & n.s. & n.s. & n.s. & -3.4772 \\
\hline Gm20-2/3a (Soil_9) & n.s. & 1.1289 & 0.1798 & 0.3058 & n.s. & 3.7156 & 0.6415 \\
\hline I-K-2C (Soil_10) & -2.7090 & 1.8606 & -1.8423 & n.s. & 1.3232 & n.s. & 3.3136 \\
\hline I-Y-2C (Soil_11) & 0.4994 & 0.4537 & n.s. & 0.5158 & n.s. & 7.6462 & 1.1321 \\
\hline I-BH-U-C (Soil_12) & 0.5178 & 0.6890 & -0.4127 & 0.7754 & n.s. & 4.0914 & 0.9727 \\
\hline Hg6-2/3a (Soil_13) & 0.3548 & -0.7586 & 0.9411 & 0.4694 & n.s. & 6.4765 & 0.5742 \\
\hline J2-2a (Soil_14) & 2.3345 & n.s. & 0.9976 & -1.9142 & n.s. & 2.5272 & -1.7082 \\
\hline Lg1-2b (Soil_15) & n.s. & -18.2998 & n.s. & 1.0302 & n.s. & n.s. & n.s. \\
\hline Yh2-1b (Soil_16) & n.s. & n.s. & 0.8014 & 1.2989 & -0.3218 & 6.4905 & 1.4371 \\
\hline I-Bh-2c (Soil_17) & n.s. & 0.3667 & n.s. & n.s. & n.s. & 5.9017 & 1.9701 \\
\hline WAT (Soil_18) & -1.0158 & -0.6522 & -3.3175 & n.s. & 10.0656 & n.s. & 2.0486 \\
\hline I-X1-2c (Soil_19) & n.s. & n.s. & 1.4065 & 1.3493 & 1.1067 & 6.4157 & 0.8550 \\
\hline I-B-U-2c (Soil_20) & -0.9316 & -1.2753 & -1.3537 & 3.9771 & 2.5932 & 5.5994 & n.s. \\
\hline ROC & 0.93 & 0.95 & 0.82 & 0.94 & 0.98 & 0.97 & 0.90 \\
\hline
\end{tabular}

Note: n.s., not significant at the 0.05 level

Soil_1 to Soil_20 show the code for the FAO soil classification, e.g., the FAO Soil code (soil_number) 
(a)

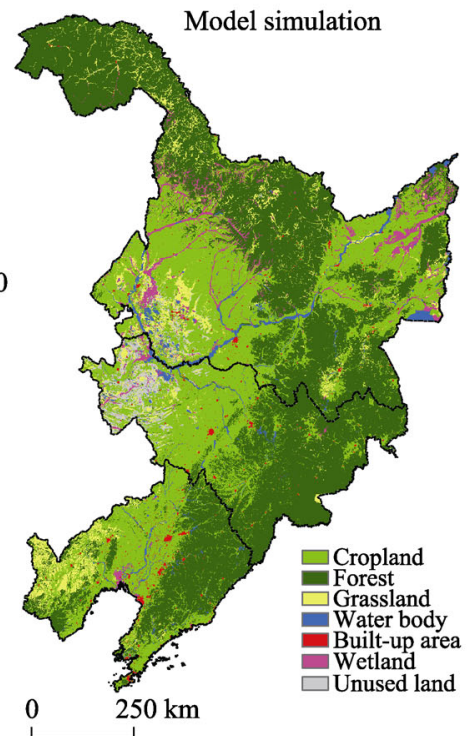

(c)

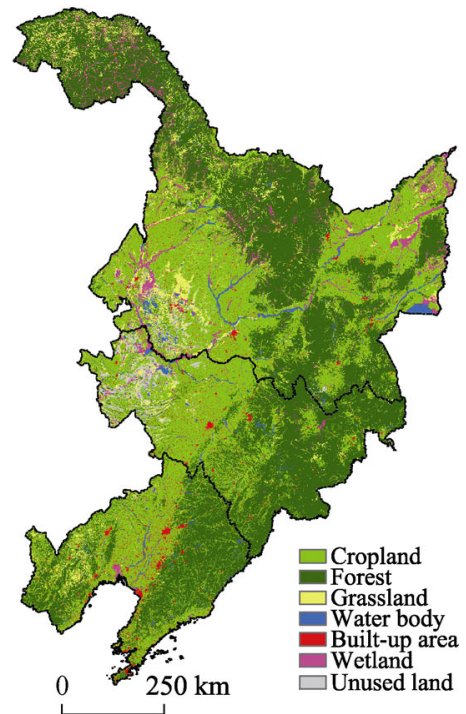

(b)

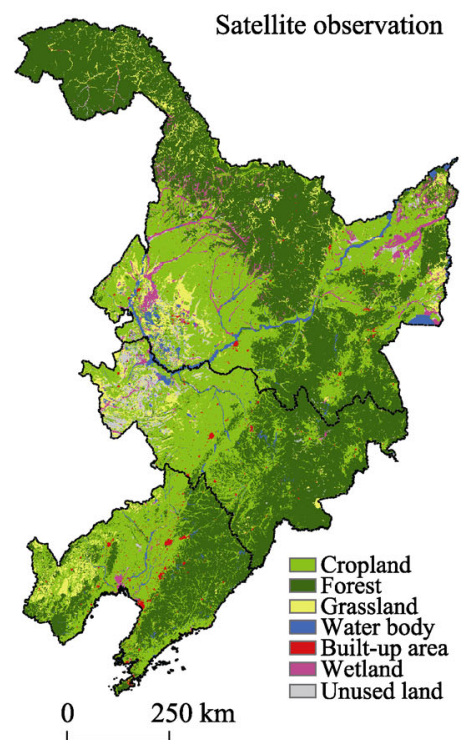

(d)

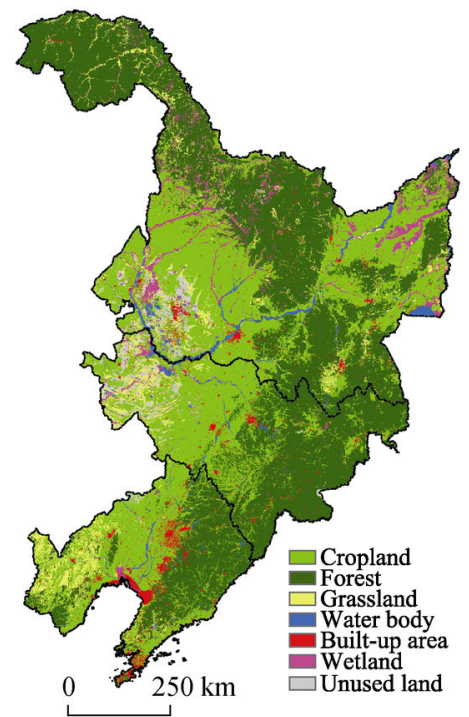

Figure 2 Comparison between model simulation (left) and satellite observation (right) in 1990 and 2005

\subsection{General patterns of land use changes in NEC}

Table 4 presents the general trend in changes in aggregated areas for each land use type in NEC for the overall period of 1980-2010. It can clearly be seen that in general, all land use types showed an obvious change in total area, but there were noticeable differences among the seven land use types for the three sub periods.

From 1980 to 1990, given the rapid development of agriculture in NEC, land use changes featured an obvious expansion of cropland. This expansion largely occurred in the western part of NCE, as shown in Figure 3. In total, cropland increased by $12,590 \mathrm{~km}^{2}$, of which $5468 \mathrm{~km}^{2}, 4394 \mathrm{~km}^{2}$ and $1231 \mathrm{~km}^{2}$ were converted from forest, grassland and wetland, respectively. Very little cropland was lost during this period. A very small amount of grassland 
Table 4 Conversion matrix between seven land use types $\left(\mathrm{km}^{2}\right)$

\begin{tabular}{|c|c|c|c|c|c|c|c|c|c|}
\hline & $\begin{array}{c}\text { From } \\
\text { To }\end{array}$ & Cropland & Forest & Grassland & $\begin{array}{l}\text { Water } \\
\text { body }\end{array}$ & $\begin{array}{c}\text { Built-up } \\
\text { area }\end{array}$ & Wetland & $\begin{array}{c}\text { Unused } \\
\text { land }\end{array}$ & $\begin{array}{l}\text { Sum of } \\
\text { decrease }\end{array}$ \\
\hline \multirow{8}{*}{$\begin{array}{c}1980 \\
- \\
1990\end{array}$} & Cropland & - & 0 & 0 & 0 & 12 & 0 & 0 & 12 \\
\hline & Forest & 5468 & - & 0 & 11 & 0 & 0 & 5 & 5484 \\
\hline & Grassland & 4394 & 0 & - & 0 & 214 & 0 & 0 & 4608 \\
\hline & Water body & 758 & 0 & 0 & - & 0 & 0 & 0 & 758 \\
\hline & Built-up area & 0 & 0 & 0 & 0 & - & 0 & 0 & 0 \\
\hline & Wetland & 1231 & 6 & 7 & 0 & 9 & - & 0 & 1253 \\
\hline & Unused land & 739 & 11 & 0 & 0 & 18 & 0 & - & 768 \\
\hline & Sum of increase & 12590 & 17 & 7 & 11 & 241 & 0 & 5 & - \\
\hline \multirow{8}{*}{$\begin{array}{c}1990 \\
- \\
2000\end{array}$} & Cropland & - & 5630 & 680 & 529 & 152 & 921 & 78 & 7990 \\
\hline & Forest & 9619 & - & 1003 & 208 & 8 & 752 & 113 & 11703 \\
\hline & Grassland & 5896 & 283 & - & 58 & 58 & 35 & 2 & 6332 \\
\hline & Water body & 1415 & 92 & 24 & - & 0 & 11 & 0 & 1542 \\
\hline & Built-up area & 0 & 0 & 26 & 0 & - & 0 & 2 & 28 \\
\hline & Wetland & 1015 & 31 & 2 & 17 & 1 & - & 15 & 1081 \\
\hline & Unused land & 2632 & 196 & 0 & 0 & 4 & 0 & - & 2832 \\
\hline & Sum of increase & 20577 & 6232 & 1735 & 812 & 223 & 1719 & 210 & - \\
\hline \multirow{8}{*}{$\begin{array}{c}2000 \\
- \\
2010\end{array}$} & Cropland & - & 17140 & 5277 & 0 & 5711 & 360 & 1833 & 30321 \\
\hline & Forest & 7774 & - & 5275 & 0 & 4469 & 298 & 637 & 18453 \\
\hline & Grassland & 6324 & 13757 & - & 0 & 907 & 0 & 4703 & 25691 \\
\hline & Water body & 1428 & 162 & 280 & - & 0 & 588 & 26 & 2484 \\
\hline & Built-up area & 22 & 1 & 6 & 0 & - & 0 & 3 & 32 \\
\hline & Wetland & 9406 & 3068 & 4068 & 2 & 71 & - & 218 & 16833 \\
\hline & Unused land & 1218 & 162 & 10181 & 0 & 669 & 110 & - & 12340 \\
\hline & Sum of increase & 26172 & 34290 & 25087 & 2 & 11827 & 1356 & 7420 & - \\
\hline
\end{tabular}

was converted into built-up areas due to the population increase.

During 1990-2000, cropland continued to expand, with the conversion of a further 20,577 $\mathrm{km}^{2}$, but it also lost $7990 \mathrm{~km}^{2}$, resulting in a net increase of $12,587 \mathrm{~km}^{2}$. It can be seen from Figure 3 that cropland expansion was mainly located in the northern and eastern parts, rather than being widespread throughout NEC. Similar to the first period, forest and grassland were the major sources of cropland gain, with $9619 \mathrm{~km}^{2}$ of forest and $5896 \mathrm{~km}^{2}$ of grassland converted into cropland during this period. Figure 4 shows that a part of the forest in the Changbai Mountain region and grassland near Nuluerhu Mountain were converted into cropland. Moreover, some areas of water bodies and unused land in Songnen Plain were exploited and used for cropland. Loss of cropland was largely due to reforestation. About 5630 $\mathrm{km}^{2}$ of cropland was converted into forest mainly in the central part of NEC and in the west of the Changbai Mountain region.

During the recent period of 2000-2010, land use changes were even more profound. Cropland in NEC expanded quickly, in particular in Heilongjiang Province. Surprisingly, these increases largely came from wetland $\left(9406 \mathrm{~km}^{2}\right)$, followed by forest $\left(7774 \mathrm{~km}^{2}\right)$ and 
grassland $\left(6324 \mathrm{~km}^{2}\right)$. Wetland was most reduced in the Sanjiang Plain, where it was converted into rice fields. During this period, a large amount of NEC cropland was replaced by forest $\left(17,140 \mathrm{~km}^{2}\right)$, grassland $\left(5277 \mathrm{~km}^{2}\right)$ and built-up areas $\left(5711 \mathrm{~km}^{2}\right)$. Figure 4 shows that there were some areas of cropland in the Lesser Khingan Mountains and the Changbai Mountain region that were changed to forest, and conversion from cropland to grassland occurred in the Nuluerhu Mountain region and the Songnen Plain. Contrary to the previous two periods, the total area of cropland in NEC experienced a net decrease of $4149 \mathrm{~km}^{2}$. Forest area increased substantially during the period 2000-2010 at the expense of grassland, cropland and wetland. Built-up areas also increased rapidly in NEC due to urbanization and industrialization, with cropland and forest being the two major contributors to increased construction areas. Wetland and unused land decreased, being replaced by other land use types.
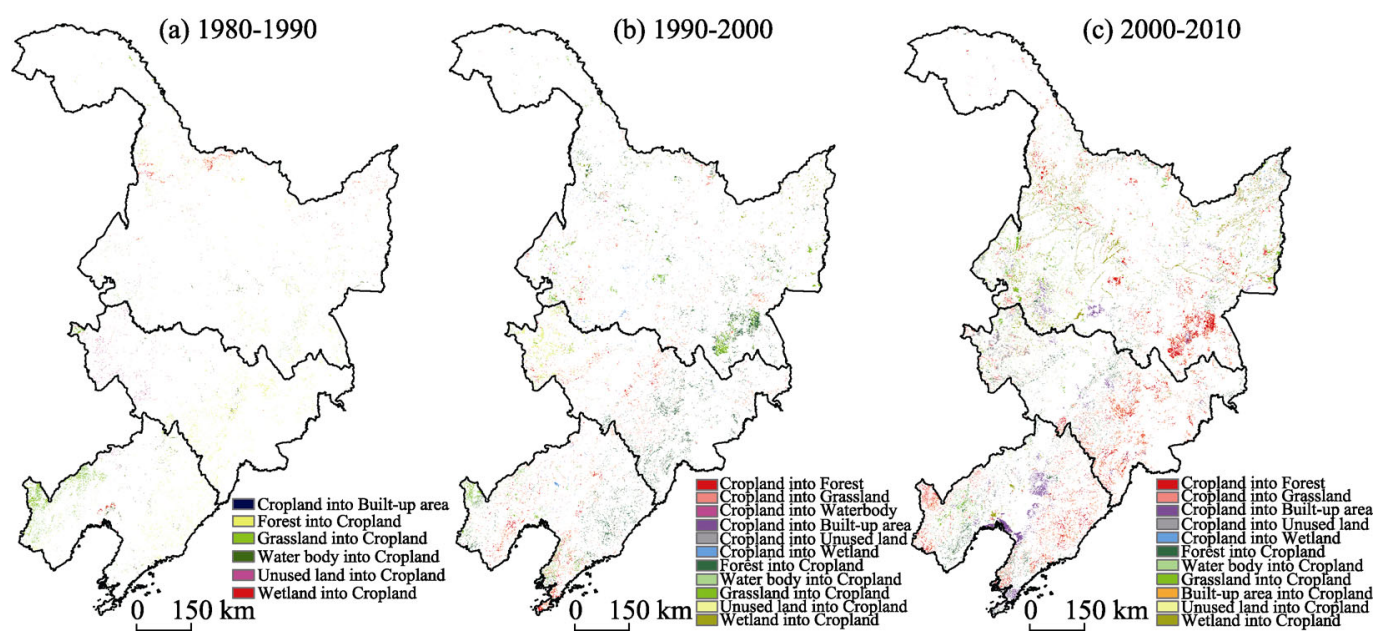

Figure 3 Spatio-temporal changes in cropland during the period 1980-1990 (a), 1990-2000 (b) and 2000-2010 (c)

\subsection{Land use changes in specific regions}

Five representative regions (A-E) in NEC are shown in Figure 4. These were selected for in-depth analysis of land use changes during the period of 1980-2010. The Lesser Khingan Mountains region (region A in Figure 4) is abundant in forest resources, most of which are primary forest. The simulated results show that there was little land use change between 1980 and 2000, yet since 2000 a large amount of grassland and wetland surrounding the existing forest areas has been converted to forest. This is largely related to regional policy. The State Forestry Administration launched a new Forest Protection Project in 1998, and this started to take effect in 2000, which caused increases in forest resources in this region. Meanwhile, some sparse forests were converted into cropland in the transitional zone between forest and cropland. Region B in Figure 4 is the Songnen Plain region, one of the most important food producing regions in China. In addition to the major land use types (i.e., cropland, grassland and wetland), unused land, mainly covered by saline and alkaline soils, is also widespread (Yao et al., 2015). Commencing in 2000, the local government invested heavily in an attempt to solve this land degradation, with several ecological construction projects implemented (Ye and Van Ranst, 2009; Ye et al., 2008). As a result, large areas of 

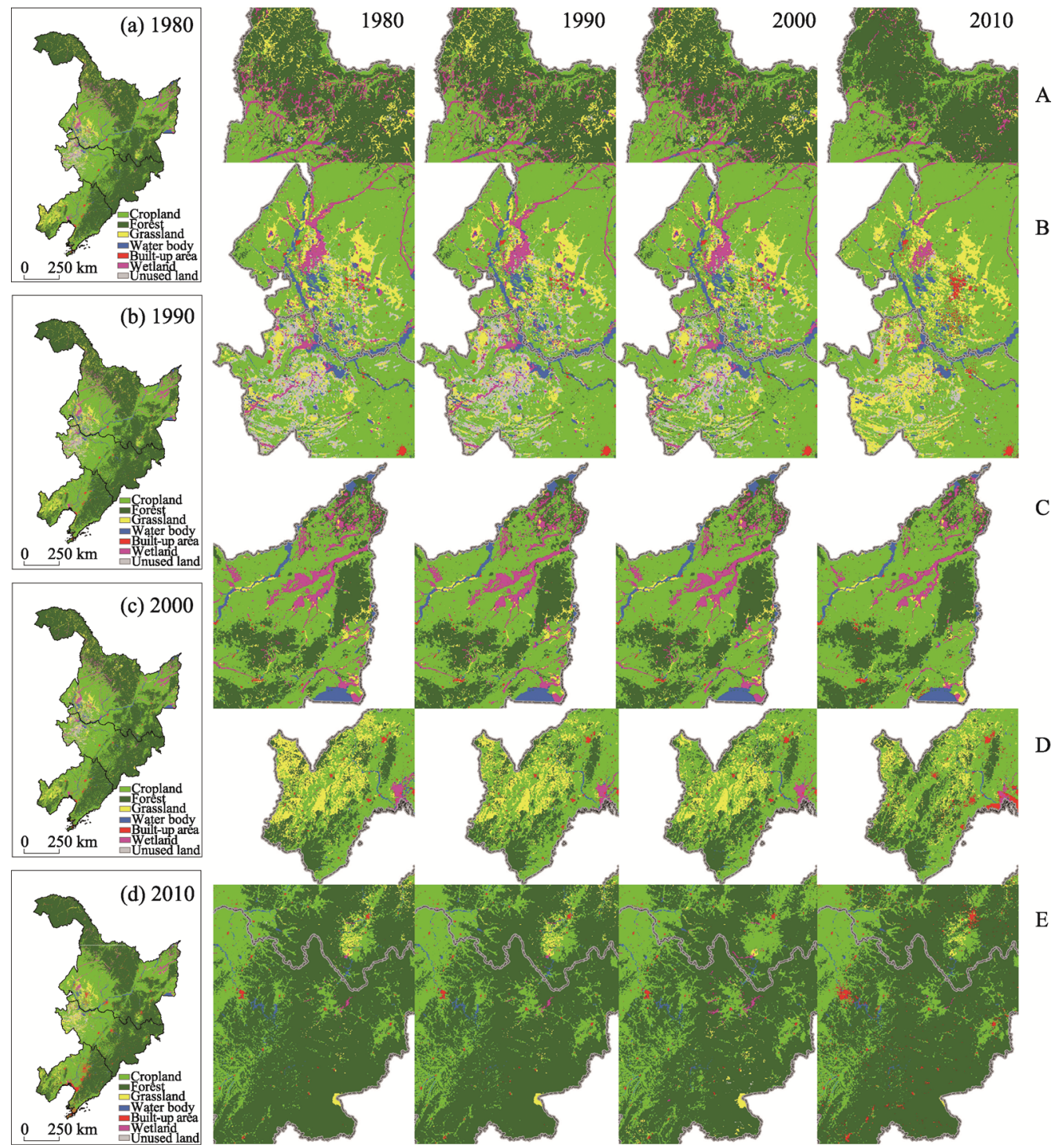

Figure 4 Simulated land use maps in 1980, 1990, 2000 and 2010 for five regions (A-E)

unused land were transferred to grassland between 2000 and 2010, which is shown by the simulated results in Figure 4. Another trend in land use change in this region is the rapid development of urbanization, driven by a series of new policies for economic revitalization. Under these conditions, built-up areas increased significantly, mainly at the expense of surrounding cropland and grassland.

The Sanjiang Plain (region C in Figure 4), where the Heilongjiang, Songhua and Wusuli Rivers are confluent, is currently one of the most important grain production bases in China. As the lowest plain in eastern Heilongjiang Province, it embraces the most concentrated and widely scattered wetlands in China. It can be observed from Figure 4 that large areas of wetland and forest have been converted to croplands since 1980 to increase food production. In particular, since 2000 in the northern part of the Sanjiang Plain, rice fields have replaced 
wetland, as this is an easy, low-cost change. The Nuluerhu Mountain region (region D in Figure 4) is located in the western part of the Liaohe Plain and is bordered by Liaoning Province and Inner Mongolia Autonomous Region. Cropland in this region expanded extensively into grasslands up until 2000. However, after 2000, cropland was gradually converted to forest due to the implementation of the Grain for Green Project. Meanwhile, some grassland was also converted to forest to increase forest resources. The Changbai Mountain region (region E in Figure 4) shows similar trends to the Nuluerhu Mountain region. It experienced an obvious increase in croplands between 1980 and 2000, forest and grassland being the major sources of cropland expansion. After 2000, croplands in the hilly and sloping regions were converted to forest under the Grain for Green Project. Moreover, in response to the blooming of tourism in this region since 2000, some small or medium-sized cities developed rapidly, and built-up areas increased substantially. These newly built-up areas were mainly conversions from cropland and forest surrounding the cities.

\section{Discussion}

\subsection{Two-directional simulation strategy}

The CLUE-S model was used to capture overall patterns of land use changes in NEC over a period of approximately 30 years (1980-2010) at a resolution of $1 \mathrm{~km}$. To do so, the year 2000 was selected as the baseline year due to the lack of land use data and driving factor data for the year 1980. This study is thus characterized by the fact that the CLUE-S model employs a strategy of two-directional simulation. To ensure realistic and consistent simulated results of land use change analysis, a forward simulation for the period 2000-2010 and a backward simulation for the period 1980-2000 were carried out. This is different from previous studies, which normally used the CLUE-S model for forward simulation only. This application of backward simulation in this study is thus a good experiment. In fact, backward simulation differs from forward simulation in model parameterization. The transformation matrix and conversion elasticity had to be set independently according to different characteristics of the two simulation periods. For instance, conversion from built-up area to cropland is very unlikely in the forward simulation, but it frequently occurs in the backward simulation. The validation results showed a fairly high accuracy in both forward and backward simulation, suggesting that the strategy of two-directional simulation can enrich CLUE-S model applications in the future when input data are limited. However, uncertainty also remains due to the hard classification scheme used here. Although it is widely used for mapping land use types, it largely overlooks the representation of land systems (Turner II, 2013; Verburg, 2013) because the landscape is normally a mosaic, and should not be simply designated as one land use type, particularly at a coarse resolution of $1 \mathrm{~km}^{2}$. Future studies should introduce the land system concept into model simulation (Václavík et al., 2013; van Asselen et al., 2013).

\subsection{The causes of land use changes}

Logistic analysis results showed that biophysical and socioeconomic factors have a great effect on land use changes, but different influences among individual land use types. 
Changes in cropland, forest and grassland are mainly affected by climate change, topography and soil conditions, while changes in built-up areas are more influenced by the terrain and economic factors (Ye et al., 2013, 2015). The distribution of wetland and unused land are largely negatively correlated with GDP, population, land aspect and slope. Using these major driving factors, the distribution probability of individual land use types can be determined for specific locations. The factors with high correlation coefficients are used by the probability function for the corresponding land use types, while the factors with low significant are left out. Moreover, land use policy also plays an important role in land use changes. During the period of 1980-1990, NEC experienced slow economic progress, and the government was more concerned about food security issues. As a result, land use changes were not frequent, and occurred mainly in the southern part of NEC, where some forest and grassland areas were converted into cropland. The economy of NEC started to grow quickly after 1990. Increasing demand for food caused a large number of scattered forest, grassland and unused land areas been converted into cropland in the middle of NEC between 1990 and 2000. At the same period, the overexploitation of cropland led to ecological problems, i.e., land degradation and deterioration (Bindraban et al., 2012; Ye and Van Ranst, 2009). Consequently, new land use policies, such as returning cropland to forest, were implemented, which caused significant conversion of cropland into forest in NEC. During the period 2000-2010, rapid economic development was the top item on the local government agenda. The increasing demand for built-up areas caused the disappearance of a large amount of cropland and forest surrounding the cities. In order to achieve a dynamic equilibrium in terms of total cropland, some wetland and forest areas were transferred to cropland in the northern part of NEC. This study included some limited areas of changing such as national nature reserve park to express the policies influence. However, it is hard to fully consider all the influence of policy factors. It should be thus acknowledged that although the selected factors can effectively explain the changes in the distribution of various land use types, some other causes, e.g., policy change, technological development and social preferences, which may also have a great impact on land use changes, were not considered in this study. This suggests some uncertainties in the final simulation results. This study only identified the major factors driving the land use changes, but the relative contribution of each factor should be explored further in the future research.

\subsection{The implications of land use changes}

This study showed that the NEC experienced an obvious land use changes over the period of 1980-2010. In particular, cropland constantly expanded northward during this period. The loss of cropland due to urbanization and industrialization in the southern part of NEC triggered more cropland conversion in the north, where there is more potentially available cropland. Moreover, global warming has had a positive impact on cropland expansion in the North, particularly in the Sanjiang Plain, where rice cultivation has expanded over the past 30 years at the expense of wetland and grassland (Xia, 2014). Although the new cropland could substantially increase national and regional food security, uncertain impacts on the environment and potentially detrimental system feedback could undermine future food production. For instance, the rapid decrease in wetland areas could damage the whole ecosystem and devastate the overall environmental resources of NEC, as wetlands have multiple 
roles to play as water resources and in terms of biodiversity protection, animal-bearing capacity and other ecological functions. Effective laws and regulations are required for wetland conservation. Future land use management should take these trade-offs into consideration. The land use systems in general must become fully sustainable, which will require new approaches to address the interwoven challenges of food production and environmental protection (An et al., 2007).

\section{Conclusions}

This study used the CLUE-S model to analyze the spatio-temporal changes in land use in NEC over the past 30 years. The model implemented both forward (2000-2010) and backward (1980-2000) simulations, taking the year 2000 as the baseline. Biophysical and socioeconomic factors could impact land use changes, but with different influences on individual land use types. Land use policy also played an important role in land use changes in NCE. The changing patterns in land use types differed. Distribution of cropland and forestland in NEC showed a clear X-shaped pattern. That is, cropland spanned the areas from the northeast (the Sanjiang Plain) to the southwest (the Liaohe Plain), while forestland ranged from the northwest (the Lesser Khingan Mountains) to the southeast (the Changbai Mountains). Increases in cropland area accounted for $33,167 \mathrm{~km}^{2}$ in NEC, and were mainly distributed in the Sanjiang Plain and the Songnen Plain during 1980-2000; and new croplands were mostly converted from forestlands and grasslands. After the year 2000, although new cropland was still gained from wetland in the Sanjiang Plain, a net loss of cropland area of $30,321 \mathrm{~km}^{2}$ was characterized. Changes of forestland area showed an opposite pattern to that of cropland. An area of $17,183 \mathrm{~km}^{2}$ of forestland was found lost in the Khingan Mountains and the Changbai Mountains between 1980 and 2000, followed by a small gain of $6249 \mathrm{~km}^{2}$ from neighbouring croplands and grasslands. Findings from this paper improved our understanding over the causes, locations and consequences of land use changes, and provided important support in land use planning and policy making to ensure sustainable management and use of land resources.

\section{Acknowledgements}

The research described in this paper is supported and financed by the National Natural Science Foundation of China (41201089 and 41271112); The Fundamental Research Funds for the Central Universities (CCNU15A05058); National Nonprofit Institute Research Grant of CAAS (IARRP-2015-28). We also thank all the persons and institutes who have kindly made their data available for this analysis.

\section{References}

An S, Li H, Guan B et al., 2007. China's natural wetlands: Past problems, current status, and future challenges. Ambio, 36(4): 335-342.

Bakker M, Veldkamp A, 2012. Changing relationships between land use and environmental characteristics and their consequences for spatially explicit land-use change prediction. Journal of Land Use Science, 7(4): 407-424. 
Bindraban P S, van der Velde M, Ye L et al., 2012. Assessing the impact of soil degradation on food production. Current Opinion in Environmental Sustainability, 4(5): 478-488.

Brown D G, Verburg P H, Pontius Jr R G et al., 2013. Opportunities to improve impact, integration, and evaluation of land change models. Current Opinion in Environmental Sustainability, 5(5): 452-457.

Chen X, Fan R, Shi X et al., 2013. Spatial variation of penetration resistance and water content as affected by tillage and crop rotation in a black soil in Northeast China. Acta Agriculturae Scandinavica Section B-Soil and Plant Science, 63(8): 740-747.

Costanza R., 1989. Model goodness of fit: A multiple resolution procedure. Ecological Modelling, 47(3/4): $199-215$.

Foley J A, 2005. Global consequences of land use. Science, 309(5734): 570-574.

Gao J, Liu Y, 2011. Climate warming and land use change in Heilongjiang Province, Northeast China. Applied Geography, 31(2): 476-482.

Geoghegan J, Villar S C, Klepeis P et al., 2001. Modeling tropical deforestation in the southern Yucatán peninsular region: Comparing survey and satellite data. Agriculture, Ecosystems \& Environment, 85(1-3): 25-46.

Gong P, Wang J, Yu L et al., 2013. Finer resolution observation and monitoring of global land cover: First mapping results with Landsat TM and ETM+ data. International Journal of Remote Sensing, 34(7): 2607-2654.

Gutman G, Huang C, Chander G et al., 2013. Assessment of the NASA-USGS global land survey (GLS) datasets. Remote Sensing of Environment, 134: 249-265.

Lambin E.F., Geist H., 2006. Land-use and Land-cover Change. Berlin Heidelberg: Springer.

Lambin E F, Turner B L, Geist H J et al., 2001. The causes of land-use and land-cover change: Moving beyond the myths. Global Environmental Change, 11(4): 261-269.

Letourneau A, Verburg P H, Stehfest E, 2012. A land-use systems approach to represent land-use dynamics at continental and global scales. Environmental Modelling \& Software, 33: 61-79.

Li S, Verburg P H, Lv S et al., 2012. Spatial analysis of the driving factors of grassland degradation under conditions of climate change and intensive use in Inner Mongolia, China. Regional Environmental Change, 12(3): 461-474.

Li Z, Tang H, Yang P et al., 2012. Spatio-temporal responses of cropland phenophases to climate change in Northeast China. Journal of Geographical Sciences, 22(1): 29-45.

Liu J, Liu M, Tian H et al., 2005. Spatial and temporal patterns of China's cropland during 1990-2000: An analysis based on landsat tm data. Remote Sensing of Environment, 98(4): 442-456.

Liu J, Liu M, Zhuang D et al., 2003. Study on spatial pattern of land-use change in China during 1995-2000. Science in China Series D: Earth Sciences, 46(4): 373-384.

Liu Y, Wang D, Gao J et al., 2005. Land use/cover changes, the environment and water resources in Northeast China. Environmental Management, 36(5): 691-701.

Pontius Jr R G, Cornell J D, Hall C A S, 2001. Modeling the spatial pattern of land-use change with geomod2: Application and validation for Costa Rica. Agriculture, Ecosystems \& Environment, 85(1-3): 191-203.

Pontius Jr R G, Schneider L C, 2001. Land-cover change model validation by an ROC method for the Ipswich watershed, Massachusetts, USA. Agriculture, Ecosystems \& Environment, 85(1-3): 239-248.

Pontius R G, Huffaker D, Denman K, 2004. Useful techniques of validation for spatially explicit land-change models. Ecological Modelling, 179(4): 445-461.

Rounsevell M, Annetts J E, Audsley E et al., 2003. Modelling the spatial distribution of agricultural land use at the regional scale. Agriculture, Ecosystems \& Environment, 95(2): 465-479.

Rounsevell M D A, Reginster I, Araújo M B et al., 2006. A coherent set of future land use change scenarios for europe. Agriculture, Ecosystems \& Environment, 114(1): 57-68.

Schaldach R U D, Alcamo J, Koch J et al., 2011. An integrated approach to modelling land-use change on continental and global scales. Environmental Modelling \& Software, 26(8): 1041-1051.

Serneels S, Lambin E F, 2001. Proximate causes of land-use change in Narok District, Kenya: A spatial statistical model. Agriculture, Ecosystems \& Environment, 85(1-3): 65-81.

Sleeter B M, Sohl T L, Loveland T R et al., 2013. Land-cover change in the conterminous United States from 1973 to 2000. Global Environmental Change, 23(4): 733-748. 
Turner II B L, Janetos A C, Verburg P H et al., 2013. Land system architecture: using land systems to adapt and mitigate global environmental change. Global Environmental Change, 23(2): 395-397.

Václavík T., Lautenbach S., Kuemmerle T. et al., 2013. Mapping global land system archetypes. Global Environmental Change, 23(6): 1637-1647.

van Asselen S., Verburg P.H., 2013. Land cover change or land-use intensification: Simulating land system change with a global-scale land change model. Global Change Biology, 19(12): 3648-3667.

van Vliet J, Bregt A K, Hagen-Zanker A, 2011. Revisiting kappa to account for change in the accuracy assessment of land-use change models. Ecological Modelling, 222(8): 1367-1375.

Veldkamp A, Fresco L O, 1996. Clue: A conceptual model to study the conversion of land use and its effects. Ecological Modelling, 85(2/3): 253-270.

Verburg P H, Erb K, Mertz O et al., 2013. Land system science: Between global challenges and local realities. Current Opinion in Environmental Sustainability, 5(5): 433-437.

Verburg P H, Neumann K, Nol L, 2011. Challenges in using land use and land cover data for global change studies. Global Change Biology, 17(2): 974-989.

Verburg P H, Overmars K P, Huigen M G et al., 2006. Analysis of the effects of land use change on protected areas in the philippines. Applied Geography, 26(2): 153-173.

Verburg P H, Schot P P, Dijst M J et al., 2004. Land use change modelling: Current practice and research priorities. Geojournal, 61(4): 309-324.

Verburg P H, Schulp C, Witte N et al., 2006. Downscaling of land use change scenarios to assess the dynamics of European landscapes. Agriculture, Ecosystems \& Environment, 114(1): 39-56.

Verburg P H, Soepboer W, Veldkamp A et al., 2002. Modeling the spatial dynamics of regional land use: The CLUE-S model. Environmental Management, 30(3): 391-405.

White R, Engelen G, 2000. High-resolution integrated modelling of the spatial dynamics of urban and regional systems. Computers, Environment and Urban Systems, 24(5): 383-400.

Wu W, Shibasaki R, Yang P et al., 2007. Global-scale modelling of future changes in sown areas of major crops. Ecological Modelling, 208(2-4): 378-390.

Wu W, Shibasaki R, Yang P et al., 2008. Validation and comparison of $1 \mathrm{~km}$ global land cover products in China. International Journal of Remote Sensing, 29(13): 3769-3785.

Wu W, Verburg P H, Tang H, 2014. Climate change and the food production system: Impacts and adaptation in China. Regional Environmental Change, 14(1): 1-5.

Xia T, Wu W, Zhou Q et al., 2014. Spatio-temporal changes in the rice planting area and their relationship to climate change in Northeast China: A model-based analysis. Journal of Integrative Agriculture, 13(7): 1575-1585.

Yao Y, Ye L, Tang H et al., 2015. Cropland soil organic matter content change in Northeast China, 1985-2005. Open Geosciences, 7(1), 234-243.

Ye L, Tang H, Yang G et al., 2015. Adopting higher-yielding varieties to ensure Chinese food security under climate change in 2050. Procedia Environmental Sciences, 29: 281.

Ye L, Tang H, Zhu J et al., 2008. Spatial patterns and effects of soil organic carbon on grain productivity assessment in China. Soil Use and Management, 24(1): 80-91.

Ye L, Van Ranst E, 2009. Production scenarios and the effect of soil degradation on long-term food security in China. Global Environmental Change, 19(4), 464-481.

Ye L, Xiong W, Li Z et al., 2013. Climate change impact on China food security in 2050. Agronomy for Sustainable Development, 33(2): 363-374.

Yu Q, Wu W, Verburg P H et al., 2013. A survey-based exploration of land-system dynamics in an agricultural region of Northeast China. Agricultural Systems, 121: 106-116.

$\mathrm{Yu} \mathrm{Q}, \mathrm{Wu} \mathrm{W}$, Yang P et al., 2012. Proposing an interdisciplinary and cross-scale framework for global change and food security researches. Agriculture, Ecosystems \& Environment, 156: 57-71.

Zhang S, Zhang X, Huffman T et al., 2011. Influence of topography and land management on soil nutrients variability in Northeast China. Nutrient Cycling in Agroecosystems, 89(3): 427-438. 